\title{
A fringe too far
}

\section{David Morrison finds contemporary echoes in a history of 'science wars', from Velikovsky to Lysenko and beyond.}

$\mathrm{F}$ rom creationism and climate-change denial to cold fusion, pseudoscience pervades the media, often drowning out real science. Michael Gordin's scholarly and highly readable The Pseudoscience Wars uses Immanuel Velikovsky's 'cosmic catastrophe' theory - once a hugely influential recasting of ancient history - as the organizing principle for a discussion of modern pseudoscience and "science wars". The book also covers Lysenkoism and young-Earth geology in depth.

Gordin, a science historian, asserts that scientists apply the label of pseudoscience which he defines as "doctrines that are nonscience but pretend to be, or aspire to be, or are simply mistaken for scientific" - only to ideas whose public appeal makes them seem threatening. His goal is to examine how scientists try to deal with the issue of 'outsiders' and understand their thinking, and what light the Velikovsky phenomenon sheds on that.

For much of the past half-century, Velikovsky's big idea both enjoyed public popularity and drew the opprobrium of scientists. A Russian immigrant to the United States, Velikovsky was a psychiatrist by training, yet thought of himself as a historian who used the insights of psychoanalysis to interpret the myths of early civilizations. He collected and correlated myths from the first and second millennia BC, many dealing with catastrophes such as the Egyptian plagues described in the Bible's Old Testament. Eventually, he began to propose cosmic events that could explain things that happened in the myths.

By the late 1940s, Velikovsky had convinced himself that Earth had nearly collided with Venus and Mars between 2000 and 800 BC. This grand synthesis was published in 1950 as Worlds in Collision, followed by several further books and dozens of articles. In spite of scathing criticism from other scientists, he

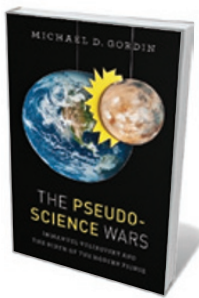

The

Pseudoscience Wars: Immanuel Velikovsky and the Birth of the Modern Fringe MICHAEL D. GORDIN University of Chicago Press: 2012. 304 pp. $£ 18.50, \$ 29$ never wavered from his conviction: a few weeks before his death in 1979, he said: "No one has disproved Worlds in Collision."

The book became a best-seller. But Velikovsky wanted to be recognized as a bona fide scholar. He was stung by harsh reviews, including pressure from prominent scientists that resulted in the book being dropped by Macmillan (which publishes this journal), then the main publisher of science textbooks in the United States, and transferred to the trade publisher Doubleday.

Velikovsky sought scientific legitimacy by courting individual scientists, especially Albert Einstein, who, like Velikovsky, lived in Princeton, New Jersey. Gordin discusses these efforts and the mainly hostile reactions to them. Scientists recognized that Velikovsky's planetary collisions, and his suggestion that electromagnetism rather than gravitation dominated planetary motions, were (in Einstein's term) "crazy". Velikovsky was simply not speaking the same language as the scientific community, yet his books were received uncritically by many of the public.

If the story had ended there, he would quickly have retreated into oblivion. But in the 1970s, Velikovsky became a symbol of the US counterculture. His reissued books hit the best-seller lists again; students invited him to speak on college campuses, and he acquired a group of enthusiastic disciples.

This assault from a crank baffled the scientific community. Gordin adds context

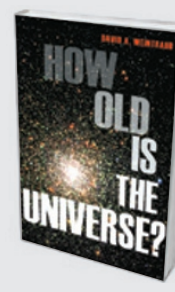

How Old Is the Universe?

David A. Weintraub (Princeton Univ. Press, 2012; \$22.95)

Astronomers do not believe the Universe is 13.7 billion years old, writes David Weintraub; they know it. But how? Weintraub chronicles centuries of scientists' painstaking work gauging the ages of planets and stars to arrive at the answer.

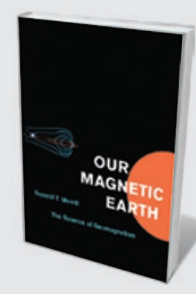

Our Magnetic Earth: The Science of Geomagnetism Ronald T. Merrill (Univ. Chicago Press, 2012; \$17.00)

Earth scientist Ronald Merrill draws together topics relating to geomagnetism, from mammals using the magnetic field for sensing to what magnetized rocks reveal about Earth's history. 
with the tale of the agronomist and pseudoscientist Trofim Lysenko, whose theory of heredity, supported by Joseph Stalin, came close to destroying the science of genetics in the Soviet Union. One reason scientists so strongly opposed Velikovsky was the recent, chilling memory of Lysenkoism.

There are fascinating and alarming parallels between these outsider narratives and Christian creationists' use of pseudoscientific arguments to lend legitimacy to their cause. Henry Morris and John Whitcomb's 1961 publication The Genesis Flood (Presbyterian and Reformed Publishing) became the foundation of the 'creation science' movement. Like Velikovsky, these authors postulated a catastrophic history of Earth, reinterpreting all geology in terms of a single universal flood, as described in chapters 6-11 of Genesis. They based their conclusions solely on a literal interpretation of scripture, and rejected Velikovsky's naturalist explanations.

Pseudoscience that has the support of organized religion or economic interests tends to survive much longer than the work of a lone eccentric such as Velikovsky. In his final pages, Gordin touches on a new phase of pseudoscience, practised by a few rogue scientists themselves. Climate-change denialism is the prime example, in which a handful of researchers, allied with an effective public-relations machine, are publicly challenging the scientific consensus that global warming is real and is attributable mainly to human consumption of fossil fuels. Deniers' questioning of the climate data and their attacks on the integrity and motivations of the scientists involved was exemplified by the e-mail-hacking 'climategate' scandal of 2009. This is perhaps the greatest threat from pseudoscience today.

Velikovsky and Lysenko may be largely forgotten, but other forms of pseudoscience are flourishing - among both the public and many politicians. Gordin's historical analysis of pseudoscience remains disturbingly relevant.

David Morrison is the director of the Carl Sagan Center for Study of Life in the Universe in Mountain View, California. e-mail:dmorrison@seti.org

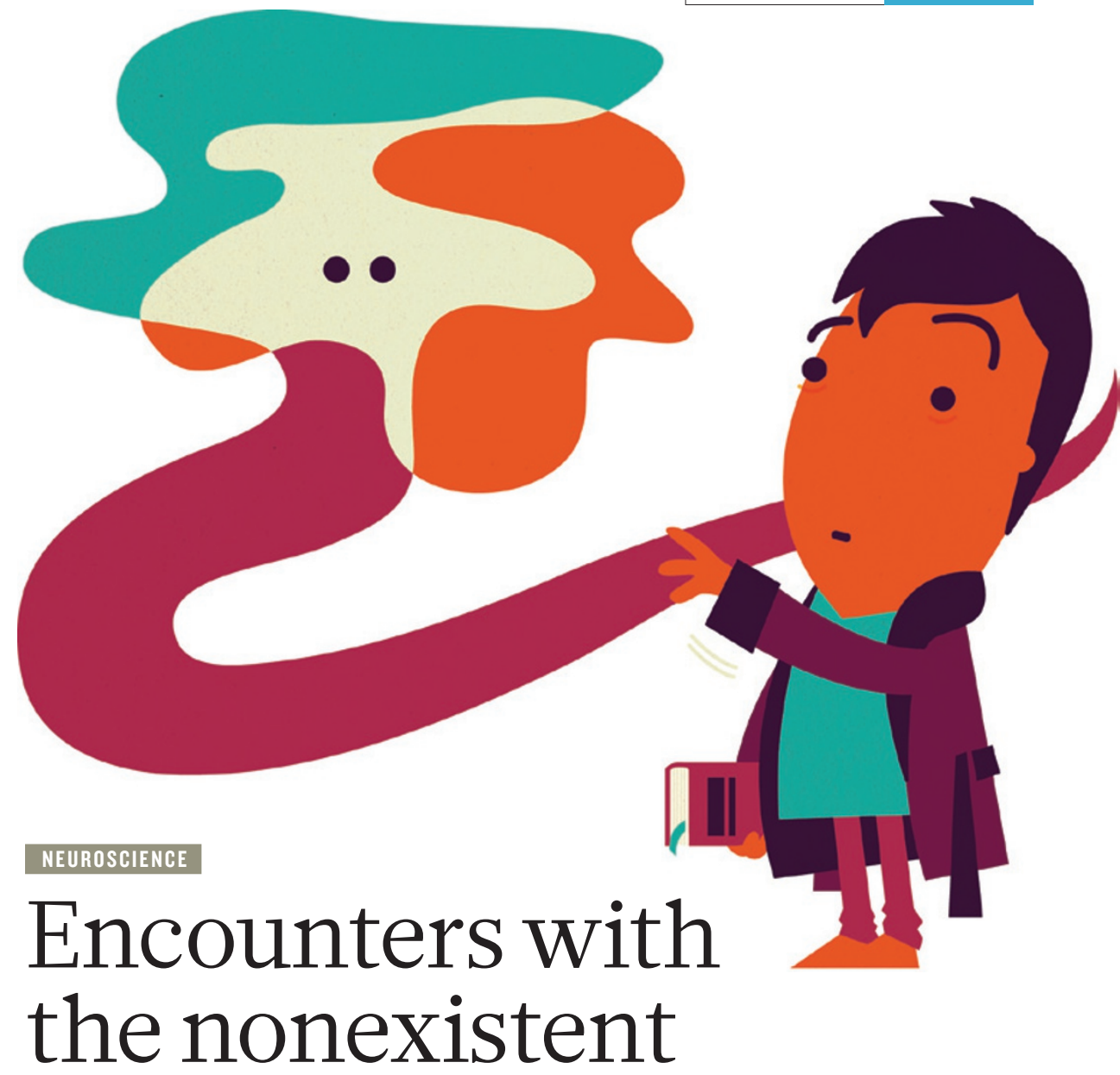

Dominic ffytche contemplates Oliver Sacks' journey through the past and future science of hallucinations.

$\mathrm{O}$ liver Sacks' Hallucinations opens with something of an apology. The neurologist explains that his book will not focus on cutting-edge brainimaging studies of what happens during a hallucination or what predisposes individuals to having them; rather, it will concentrate on first-person accounts, with the aim of understanding what it is like to hallucinate. It is as if Sacks worries that such an approach is insufficiently scientific, in an era of functional and structural neuroimaging.

Such concerns are unfounded. Imaging studies have made significant contributions to the field, but it is still Sacks' clinical territory — where the listening, archiving

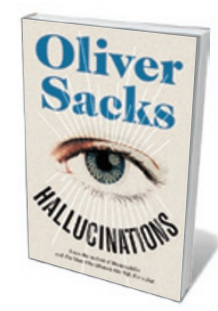

Hallucinations

OLIVER SACKS

Picador/Knopf:

2012. 336/352 pp.

$£ 18.99 / \$ 26.95$ and recognition of repeated patterns of symptoms takes place - that sets the research agenda.

By analogy to eighteenth-century catalogues of flora and fauna from different corners of the world, Sacks structures his book as a 'natural history' of hallucinations. Chapter by chapter, he describes the various clinical and physiological settings in which people have hallucinations. They might

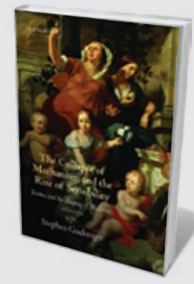

The Collapse of Mechanism and the

Rise of Sensibility

Stephen Gaukroger (Oxford Univ. Press, 2012;

£25)

Historian of philosophy Stephen Gaukroger charts how a sensory view of nature coincided with the novel's rise in 1680-1760. (See George Rousseau's review: Nature 470, 462-463; 2011.)

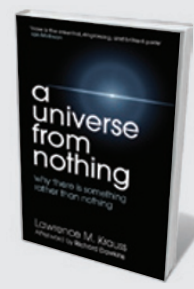

A Universe from Nothing: Why There Is

Something Rather than Nothing

Lawrence M. Krauss (Simon \& Schuster, 2012; $£ 8.99$ )

The current thinking on multiverses, dark energy and what is meant by 'nothing' is unpicked by theoretical physicist Lawrence Krauss. (See Caleb Scharf's review: Nature 481, 440; 2012.) 